\title{
NUMERICAL STUDY OF THE EXHAUST GAS FLOW OF TV3-117 TYPE ENGINES IN COMPOSITION WITH A SCREEN - EXHAUST DEVICE
}

\author{
Mykhailo Kinaschuk ${ }^{1}$ \\ ${ }^{1}$ Aircraft Engines Department, National Aviation University, Kyiv, Ukraine \\ kinaschukm.i@gmail.com \\ ORCID: http://orcid.org/0000-0002-7130-8470
}

ARTICLE INFO

A B S T R A C T

Article history:

Received date 25.06 .2020

Accepted date 22.07.2020

Published date 31.08.2020

The object of research is a screen-exhaust device in the TV3-117 engine of the Mi- 8 helicopter.

Section:

Machine building and metal processing

DO I

Investigated problem: The problem of equalizing the flow in the exhaust nozzle is solved. As a result of the numerical study, the total pressure losses are calculated and the flow structures in the structural elements of the exhaust nozzle and the screen-exhaust device (SED) are analyzed.

$10.21303 / 2313-8416.2020 .001391$

Main scientific results: Obtained Gas-dynamic parameters of the flow in the SED flow path are obtained and the verification of injection processes between the working circuits along the path in the SED design is done. Numerical modeling of gas flows in the SED flow

KEYWORDS

numerical simulation

exhaust nozzle

gas turbine engine

screen-exhaust device

total pressure loss path makes it possible to study in detail the characteristics of the flow at any of its points, as well as to determine the values of hydrodynamic losses associated with the formation of a boundary layer and the emergence of separation zones. A constructive method for leveling the gas-dynamic flow is proposed by installing a blade in the form of an aerodynamic profile in a standard engine exhaust nozzle. Two variants of engine nozzles are investigated under the same boundary conditions using a standard exhaust nozzle with and without a blade. The influence of uneven flow in the exhaust nozzle on the nature of the flow in the SED is shown. An insignificant equalization of the flow in the exhaust nozzle using the installed blade led to a decrease in the total pressure loss in the SED by more than $1 \%$.

The area of practical use of the research results: The results of calculations and modeling can be used for computational and experimental studies aimed at improving the flow path of the exhaust nozzle and the screen-exhaust device by the developers of new military aviation equipment or when modernizing the existing helicopter fleet.

Scope of application of the innovative technological product: a new screen-exhaust device has been proposed for left and right TV3-117 engines of all types, which can be installed on the Mi-8MSB-V, Mi-8MT, Mi-14, Mi-24 helicopters. It is competitive and has significantly higher technical and economic indicators compared to known analogues.

(C) The Author(s) 2020. This is an open access article under the CC BY license http://creativecommons.org/licenses/by/4.0).

\section{Introduction}

The modern doctrine of air-ground combat provides that a modern helicopter should be an autonomous multipurpose vehicle with increased strike capabilities, flight duration and range, and combat survivability. It must be capable of striking ground targets and conducting air combat at any time of the day, in any geographic area and in any weather conditions. Ukraine is not able to follow these global trends. Today its helicopter fleet is morally and physically obsolete. To achieve the level of analogues of its nearest neighbors, it needs to modernize the old, well-proven Soviet technology, which can still be modernized, and in the future, carry out licensed production of new systems [1].

One of these systems is the infrared protection system for the exhaust duct of a helicopter gas turbine engine (GTE).

GTE output device is a source of strong infrared energy that can be detected by heat-seeking missiles or various types of infrared image processing systems for targeting or tracking purposes.

To reduce the visibility in the thermal range, a system of mixing the hot exhaust gases of the engine with the ambient air is used, this method allows to reduce the infrared radiation of the engines. 
In this study, on the basis of a numerical analysis of the features of the flow of exhaust gases of a gas turbine engine in a composition with a screen-exhaust device, its new, constructive scheme is substantiated - it is more efficient in terms of hydraulic losses and is more technologically advanced in production.

\section{1. The object of research}

The object of research is a screen-exhaust device as part of the TV3-117 engine of the Mi-8 helicopter.

\section{2. Problem description}

The exhaust tract is used on helicopter gas turbine engines to divert exhaust gases in the desired direction, as well as to increase the efficiency of the engine, a certain diffuser of the exhaust channel is achieved. Such a constructive solution allows a part of the kinetic energy of the exhaust gases to be converted into compression work and to increase the pressure drop across the free turbine, and, accordingly, the power of the gas turbine engine.

In a number of engine operating modes, the gas flow at the inlet to the exhaust channel can have significant swirl. Therefore, the quality of the exhaust tract and its characteristics affect the characteristics of the entire engine.

The most reliable method for determining the output characteristic of the exhaust channel of a gas turbine engine is blowing the models. Although this method is informative, due to the complex unevenness of the flow in the real exhaust tract, the volumetric value is too low. In [2], a calculation method for determining the characteristics of the exhaust tract is presented. The essence of this method comes down to dividing a complex channel into a number of simple elements and their sequential calculation. The proximity of such a calculation method is due to the fact that the characteristics of individual diffuser elements significantly depend on the degree of uniformity of the flow at the entrance to them, which can't be calculated with a sequential arrangement of elements.

The use of a screen-exhaust device (SED) of an ejector type in a composition with a helicopter exhaust tract generally makes it impossible to apply the above methods to determine the characteristics of the exhaust tract; they vary significantly from the SED type and design.

In work [3], sources of the infrared signature of a helicopter in flight are given, as well as schematic design solutions of the SED used by leading manufacturers of combat helicopters. The qualitative indicators of the effectiveness of the SED use for shielding the heated surfaces of the GTE output devices are presented. The results of numerical modeling of the gas-dynamic flow in the SED are presented in a generalized form, which makes it impossible to compare them with the known SED designs.

Of particular scientific interest for the study and design of SED are studies of gas flow in swing bends to determine the level of total pressure losses and determine the values of hydraulic losses.

In the presented results of a numerical study [4], the analysis of the flow structure in the rotary exhaust duct of square and circular cross-sections is carried out. A comparative assessment of the level of hydraulic losses in these two cases of cross-sections makes it possible to qualitatively and quantitatively evaluate the effect of flow irregularity on the total pressure loss coefficient.

The results presented in $[5,6]$ reflect the physical picture of the gas flow in curvilinear channels, indicating the zones of flow separation and the formation of vortex structures in the flow, but the ways of flow alignment are not shown.

A number of works [7] are devoted to the theoretical study of ejectors with flow rotation. The author proposes a method for organizing a working process in a pipeline elbow, simulating the movement of gas in a SED rotary ejector [8].

On the issue of reducing the unevenness of the exhaust jet velocity field, only constructive solutions were proposed without the above research results [9].

Standard screen-exhaust devices for the Mi-8 and Mi-24 helicopters were developed in the USSR at the end of the 70s of the last century. The combat use of these helicopters by the installed SED showed a significant decrease in the impression of their portable anti-aircraft missile systems. At the same time, large (about $10 \%$ ) losses of power on the shaft of a free turbine were found and, 
as a consequence, a decrease in the maximum take-off weight, a decrease in the range and duration of the flight, as well as static and dynamic altitudes [10].

\section{3. Proposed way to solve the problem}

Traditionally, in the study of the characteristics of the exhaust tract in a composition with SED, namely the level of decrease in the gas turbine engine efficiency and power losses on the shaft of a free turbine, experimental methods were used. This led to a large amount of testing, an increase in the time and cost of prototypes. The modern possibilities of detailed modeling of physical processes by means of computational gas dynamics make it possible to obtain information on the gas-dynamic efficiency of objects requiring such a study relatively quickly compared to a physical experiment.

The aim of this research is a numerical study of the flow of exhaust gases in a screen-exhaust device with two versions of exhaust nozzles used in the TV3-117 engine.

\section{Materials and methods}

Fig. 1 shows a new screen-exhaust device for left and right TV3-117 engines of all types installed on Mi-8MSB-V, Mi-8MT, Mi-14, Mi-24 helicopters. SED designs for the left and right engines are completely identical, differ only as a mirror image of each other.

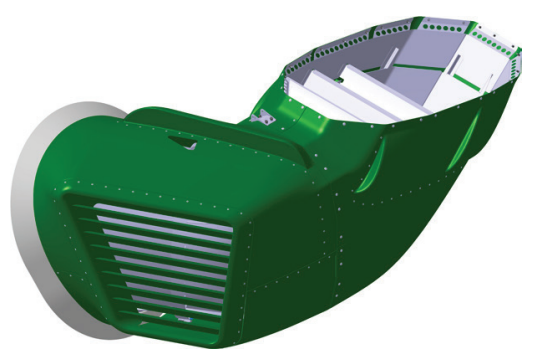

Fig. 1. Screen-exhaust device of the helicopter

SED rotary gas-dynamic contour (Fig. 2), along which the engine exhaust gases are discharged, structurally consists of the main units: receiver (1) front part of the contour (2) power belts $(3,4)$; the back of the contour (5) - seals (6).

All of the above units are made of $0.6 \ldots 1 \mathrm{~mm}$ thick heat-resistant stainless steel sheet and are interconnected by spot welding.

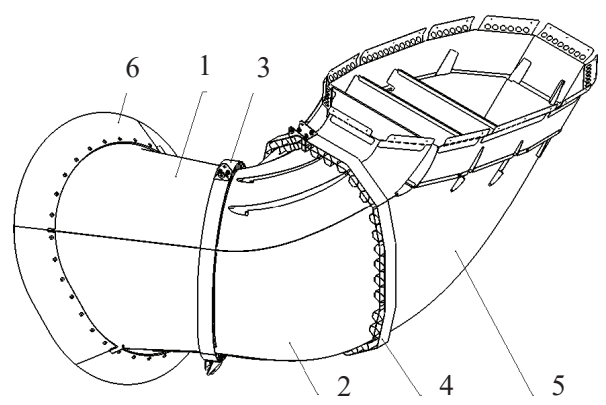

Fig. 2. Rotary gas-dynamic circuit of the screen-exhaust device

On the front edge of the receiver (1), seals are bolted, made of heat-resistant rubber (6). On the power belts $(3,4)$, the brackets for the SEW suspension on the attachment points are bolted. Straightening blades are fixed in the flow path of the gas-dynamic circuit by welding. The blades are made of sheet heat-resistant stainless steel with a thickness of $0.6 \ldots 0.8 \mathrm{~mm}$, have slots for organizing ejection processes when flowing along the contour of engine exhaust gases.

The principle of SED operation is as follows. A hot jet of engine exhaust gases enters the SED rotating gas-dynamic circuit.

A profiled gap is formed between the engine exhaust pipe and the receiver of the SED gas-dynamic circuit, which plays the role of a gas ejector. This ejector is designed to remove hot 
gases from under the hood of a helicopter. The ejection effect is enhanced by a rubber seal attached to the receiver of the gas-dynamic circuit. The seal adjoins the surface of the helicopter fuselage to isolate the internal gas flow in the SED from the external environment. The engine exhaust jet in this case plays the role of an active ejection jet.

The gas-dynamic circuit of the SED is a turning channel through which the gas jet of the engine moves. In the flowing part of the circuit, two rows of straightening blades are installed to eliminate separation and stagnant zones in order to minimize the hydraulic resistance to the flow of the gas stream. The blades (hollow, with slots along the backrest and the sharp edge of the profile) ejects a cold stream of outside air entering through the SED air intake into the space between the gas-dynamic circuit and the composite skin, and then mix with the exhaust gas flow to reduce its temperature and the temperature of the walls of these blades.

The composite sheet plays the role of a heat shield and an aerodynamic fairing for the SED. SED outlet section is located parallel to the base plane of the helicopter, providing all-aspect coverage of the hot parts of the helicopter engine from the lower hemisphere.

The operation of the gas turbine engine of screen-exhaust devices is affected due to the appearance in the exhaust tract of additional aerodynamic resistance of the exhaust gas flow, which leads to a decrease in its efficiency and power. The coefficients of the influence of the hydraulic resistance of the exhaust tract on the efficiency and power for a number of gas turbine units (GTU) are $k_{\triangle p_{e x}} \rightarrow \eta_{G T E}=-(1.0-1.3)$ and $k_{\Delta p_{e x}} \rightarrow \eta_{G T E}=-(1.0-2.2)$ [11]. The principle of operation of ground-based GTE and aircraft helicopter GTE is identical, therefore, the reduced coefficients of the influence of hydraulic resistance on the GTU characteristics can, in a certain approximation, be considered for evaluating similar GTE characteristics. There is no information on such parameters of helicopter GTE in open and accessible sources.

\section{1. Numerical modeling technique}

The numerical study was carried out in the universal Catia5-CFD CAD package/program FloEFD Mentor Graphics Corp.

The calculations were performed for the takeoff GTE operation. The flow at the inlet to the exhaust tract was assumed to be directed along the normal from the power turbine. The following were set as the boundary conditions at the entrance to the exhaust tract: the speed at the bushing diameter along the free turbine $-170 \mathrm{~m} / \mathrm{s}$; on an average diameter $-139 \mathrm{~m} / \mathrm{s}$; on the outer diameter $129 \mathrm{~m} / \mathrm{s}$; static inlet temperature $440{ }^{\circ} \mathrm{C}$; the density of the exhaust gas is $0.45 \mathrm{~kg} / \mathrm{m}^{3}$. The flow was assumed to be adiabatic, and the "sticking" boundary condition was set on the inner surfaces of the walls. The calculations were performed using the $k-\varepsilon$ turbulence model.

\section{Research results and their discussion}

For the research, 6 variants of the installed blade in the exhaust pipe of the TV-117 GTE without the SED installation were chosen. The aim of this interim study was to determine the optimal blade position to determine the minimum total pressure loss.

According to the calculation results, the total loss in the exhaust pipe is $3.1-3.3 \%$, depending on the magnitude of the action of the blade in the flow. Fig. 3 shows the flow lines in the exhaust pipe without the installed blade, in Fig. 4 with a blade installed with a minimum level of total pressure loss.

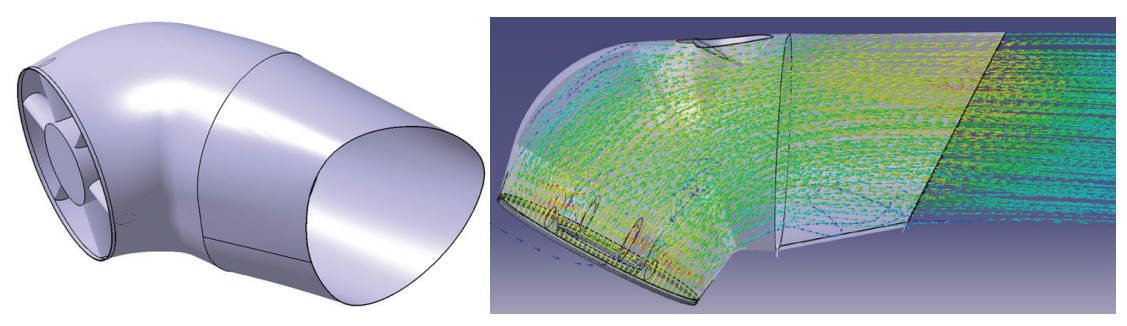

Fig. 3. The flow lines in the exhaust pipe without installed blade

In the range of $20 \ldots 60 \mathrm{~mm}$ blades per flow, the pressure loss does not change significantly (Fig. 5). 

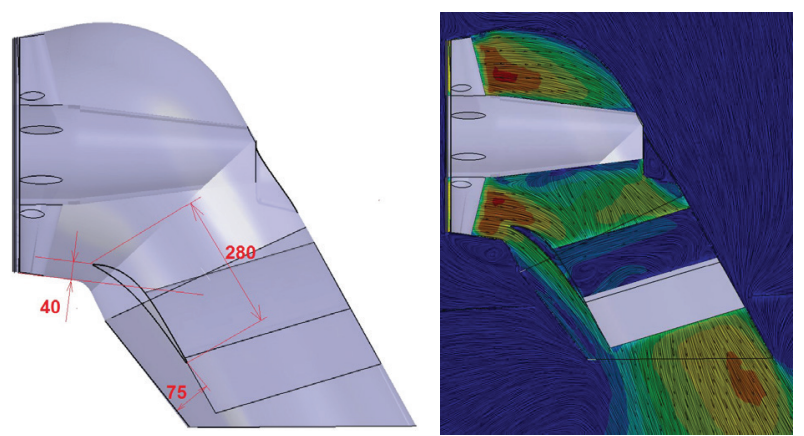

Fig. 4. The flow lines in the exhaust pipe with the installed blade

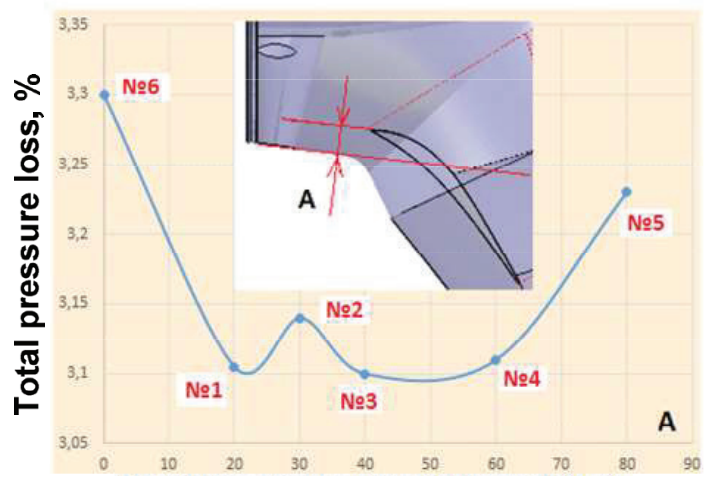

Fig. 5. Dependence of the total pressure loss on the magnitude of the blade action in the exhaust gas flow

The aim of further research was to determine the quality of the flow, the absence of secondary flows, check the injection phenomena along the path in the SED design and in the engine nozzles under the same boundary conditions using an exhaust nozzle with an installed blade and with a standard nozzle.

Fig. 6 shows the streamlines in the version with no blade in the standard branch pipe with the connected SED. The nature of the flow has a complex spatial structure with an insignificant number of vortex zones, which are concentrated in the zone of SED connection to the helicopter board around the exhaust pipe.

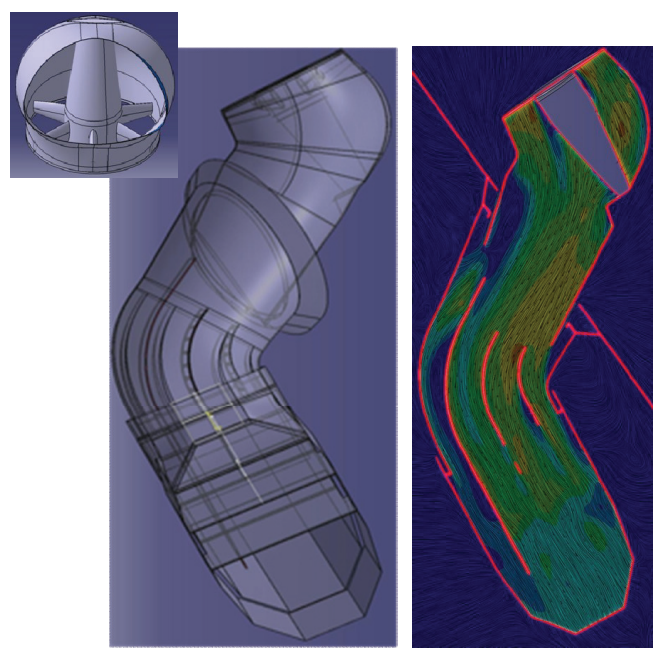

Fig. 6. Streamlines without the use of a blade in a standard branch pipe with an attached screen-exhaust device

Fig. 7 shows the streamlines in the variant with the use of a blade and a standard nozzle. The vortex zones are smaller, the flow is more uniform. 


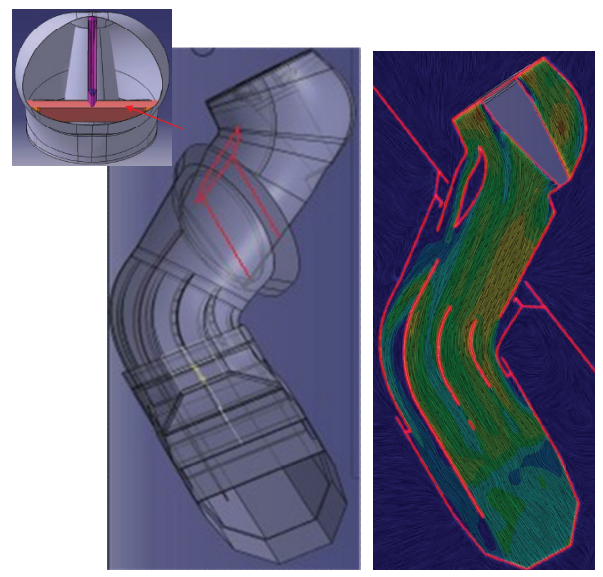

Fig. 7. Streamlines using a blade in a standard branch pipe with an attached screen-exhaust device

The results of numerical simulation showed that when the exhaust gas flow is leveled with the help of a standard exhaust nozzle (Fig. 7), the total pressure loss in the SED is $1.95 \%$, and without the installation $-3.1 \%$.

Information on local parameters obtained as a result of SED numerical simulation using a blade in a standard nozzle is given in Table $\mathbf{1}$.

Table 1

Local parameters of numerical simulation

\begin{tabular}{|c|c|c|c|c|}
\hline No. & Local parameter & Minimum & Maximum & Average value \\
\hline 1 & Pressure $[\mathrm{Pa}]$ & 90040.41489 & 168697.0444 & 102802.6187 \\
\hline 2 & Total pressure $[\mathrm{Pa}]$ & 92715.22695 & 173438.7488 & 109121.2869 \\
\hline 3 & Dynamic pressure $[\mathrm{Pa}]$ & 4.039111496 & 19994.45308 & 6159.252743 \\
\hline 4 & Density (flow medium) $\left[\mathrm{kg} / \mathrm{m}^{3}\right]$ & 0.463663434 & 0.807127118 & 0.51020332 \\
\hline 5 & Speed $[\mathrm{m} / \mathrm{s}]$ & 0.13594018 & 274.2044052 & 152.2666971 \\
\hline 6 & Speed $(\mathrm{X})[\mathrm{m} / \mathrm{s}]$ & -62.1326758 & 226.9305952 & 140.9313201 \\
\hline 7 & Speed $(\mathrm{Y})[\mathrm{m} / \mathrm{s}]$ & -194.667662 & 139.3908298 & -1.57747383 \\
\hline 8 & Speed $(\mathrm{Z})[\mathrm{m} / \mathrm{s}]$ & -207.255509 & 197.7725163 & -1.06723334 \\
\hline 9 & Mach number & 0.007631079 & 0.527588682 & 0.289284786 \\
\hline 10 & Turbulence intensity [\%] & 1.765354804 & 533.0012922 & 4.600641668 \\
\hline 11 & Turbulence energy $[\mathrm{J} / \mathrm{kg}]$ & 11.44864349 & 833.131031 & 37.43502865 \\
\hline 12 & Turbulence energy dissipation $[\mathrm{W} / \mathrm{kg}]$ & 1209.039913 & 13623487.41 & 76430.48419 \\
\hline 13 & Specific heat $(\mathrm{Cp})[\mathrm{J} /(\mathrm{kg} \cdot \mathrm{K})]$ & 1036.752578 & 1083.670655 & 1076.746447 \\
\hline 14 & Dynamic viscosity $[\mathrm{Pa} \cdot \mathrm{s}]$ & $2.80161 \mathrm{E}-05$ & $3.47566 \mathrm{E}-05$ & $3.37872 \mathrm{E}-05$ \\
\hline 15 & Temperatures (flow medium [K] & 530.4841223 & 732.6993238 & 703.6149282 \\
\hline 16 & Total temperature $[\mathrm{K}]$ & 531.0115388 & 739.2646374 & 714.9376002 \\
\hline 17 & Stagnation density $\left[\mathrm{kg} / \mathrm{m}^{3}\right]$ & 0.471841351 & 0.823887559 & 0.532778086 \\
\hline 18 & Total enthalpy $[\mathrm{J} / \mathrm{kg}]$ & 540275.5651 & 761181.5264 & 734912.3044 \\
\hline 19 & Axial speed $[\mathrm{m} / \mathrm{s}]$ & -207.255509 & 197.7725163 & -1.06708356 \\
\hline 20 & Radial speed $[\mathrm{m} / \mathrm{s}]$ & -70.0636907 & 228.1434989 & 141.3681534 \\
\hline 21 & Peripheral speed $[\mathrm{m} / \mathrm{s}]$ & -196.624207 & 146.5009507 & -1.5185775 \\
\hline 22 & Typical pressure $[\mathrm{Pa}]$ & 101325 & 101325 & 101325 \\
\hline
\end{tabular}


The shortcomings identified in the process of research in the organization of the gas-dynamic flow in the SED will be taken into account in the further constructive optimization of this device. The absence of secondary flows is observed; there are no reverse flows in the injection channels along the structure duct.

Further computational and experimental studies should be carried out in order to:

- reduction of flow irregularity from the nozzle of the helicopter engine;

- determination of the temperature distribution of exhaust gases and surfaces of SED elements taking into account heat transfer between the first and second circuits;

- verification of the results of a numerical study by comparing with the results of further experimental studies and field tests in the conditions of a helicopter flight.

\section{Conclusions}

The calculation results showed that the numerical simulation of the flow of exhaust gases in the screen-exhaust device with two variants of exhaust nozzles used as part of the TV3-117 engine in the CAD system Catia5-CFD package/program FloEFD Mentor Graphics Corp can be used not only to estimate the total pressure, but also to optimize the geometry of the designed SED.

The influence of uneven flow in the exhaust nozzle on the nature of the flow in the SED is shown. An insignificant equalization of the flow in the exhaust nozzle using the installed blade led to a decrease in the total pressure loss in the SED by more than $1 \%$.

\section{References}

[1] «Mozhlyvosti OPK Ukrainy shchodo modernizatsii boiovykh vertolotiv PS ZSU ta nalahodzhennia yikh litsenziinoho vyrobnytstva». Analitychna zapyska. Available at: http://old2.niss.gov.ua/articles/539/

[2] Maslennikov, M. M., Bekhli, Iu. G., Shalman, Iu. I. (1969). Gazoturbinnye dvigateli dlia vertoletov. Moscow: Mashinostroenie, 368.

[3] Marynowski, T., Desevaux, P., Mercadier, Y. (2009). An Investigation of Ejector Design by CFD Modelling. International Journal of Turbo and Jet Engines, 26 (1), 61-78. doi: http://doi.org/10.1515/tjj.2009.26.1.61

[4] Smyrnov, A. V., Shchedrenkov, A. N., Shcherbakov, O. N., Karutskyi, A. Yu., Parafeinyk, V. P. (2015). Chyslennoe yssledovanye techenyia haza $\mathrm{v}$ vikhlopnikh traktakh hazoperekachyvaiushchykh ahrehatov s hazoturbynnim pryvodom na baze dvyhatelia DU80L1. Visnyk dvyhunobuduvannia, 2, 199-206.

[5] Patlazhan, S. A., Vagner, S. A. (2015). Hydrodynamics of homogeneous and multiphase fluids in a narrow channel. Book of abstracts of XXX International Conference on «Interaction of Intense Energy Fluxes with Matter». Kabardino-Balkaria, Russia, 193.

[6] Germider, O. V., Popov, V. N., Yushkanov, A. A. (2017). Heat transfer process in an elliptical channel. Mathematical Models and Computer Simulations, 9 (4), 521-528. doi: http://doi.org/10.1134/s2070048217040056

[7] McGovern Ronan, K., Bulusu, K. V., Antar, M. A., Lienhard, J. H. (2012). One-Dimensional Model of an Optimal Ejector and Parametric Study of Ejector Efficiency. 25th International Conference on Efficiency, Cost, Optimization and Simulation of Energy Conversion Systems and Processes (ECOS 2012). Available at: http://hdl.handle.net/1721.1/97599

[8] Kulyk, M. S., Kozlov, V. V., Hrekov, P. I., Kinashchuk, M. I., Yasynitskyi, E. P., Doroshenko, K. V. et. al. (2013). Pat. No. 85073 UA. Cposib orhanizatsii robochoho protsesu v kolini truboprovodu. MPK (2013.01) F16L 43/00. No. u2013 05747; declareted: 07.05.2013; published: 11.11.2013, Bul. No. 1.

[9] Pat. No. 0002682804 RU. Nasadok k vykhlopnomu patrubku gazoturbinnogo dvigatelia dvukhdvigatelnoi silovoi ustanovki vertoleta. declareted: 21.03.2019, Bul. No. 1.

[10] Bashynskyi, V. H. (2013). Propozytsii po znyzhenniu infrachervonoi pomitnosti vertolotu. Systemy ozbroiennia i viiskova tekhnika, 2, 6-9.

[11] Brodov, Iu. M., Aronson, K. E., Blinkov, S. N. (2003). Teploobmenniki energeticheskikh ustanovok. Ekaterinburg: Sokrat, 964. 